\title{
Mechanism Design of Fashion Virtual Enterprise under Monitoring Strategy
}

\author{
Min Huang, ${ }^{1}$ Kegui Chen, ${ }^{1}$ Chunhui Xu, ${ }^{2}$ Wai-Ki Ching, ${ }^{3}$ and Xingwei Wang ${ }^{4}$ \\ ${ }^{1}$ College of Information Science and Engineering, State Key Laboratory of Integrated Automation for Process Industries, \\ Northeastern University, Shenyang 110819, China \\ ${ }^{2}$ Department of Risk Science in Finance and Management, Chiba Institute of Technology, Chiba 275-0016, Japan \\ ${ }^{3}$ Department of Mathematics, University of Hong Kong, Hong Kong \\ ${ }^{4}$ College of Information Science and Engineering, Northeastern University, Shenyang 110819, China
}

Correspondence should be addressed to Kegui Chen; guikechen@sina.com

Received 31 March 2014; Revised 21 June 2014; Accepted 21 June 2014; Published 6 August 2014

Academic Editor: Tsan-Ming Choi

Copyright (C) 2014 Min Huang et al. This is an open access article distributed under the Creative Commons Attribution License, which permits unrestricted use, distribution, and reproduction in any medium, provided the original work is properly cited.

Designing a revenue sharing contract to prevent the moral hazard is one of the most important issues in virtual enterprise (VE). As the partners' productive effort level cannot be observed by the owner and other partners, there is usually moral hazard problem in VE. To mitigate the moral hazard, the owner sets the monitoring effort with monitoring cost. Considering a risk-neutral owner and multiple downside risk-averse partners, the owner's problem of determining the monitoring effort and incentive intensity to maximize his profit while the partners determine their productive effort to maximize their profit is addressed. The principal agent based model of this problem is proposed. By solving the model, the optimal strategy of owner and partner is derived. By comparing with the no monitoring scenario, we find that implementing suitable monitoring strategy can reduce the moral hazard effectively. Finally, by analyzing the partners' risk attitude, the result reveals that the lower the risk level of the partner is, the more the owner wants. These results suggest that VE should not only focus on the risk attitude but also on monitoring.

\section{Introduction}

A virtual enterprise (VE) is usually defined as a temporary alliance of enterprises that come together to share their skills, core competencies, and resources in order to better respond to business opportunities and whose cooperation is supported by computer networks [1-3]. Two keyword elements in this definition are the networking and the cooperation [4]. These explain the importance of VE to further technological competencies. As the VE environment continues to grow in size and complexity, the importance of managing such complexity increases.

The advantages of virtual enterprises are the sharing of risk, cost and skill by which the efficiency of the alliance can be improved. Many organizations are entering VEs to catch the new opportunities quickly and overcome the risks associated with the opportunities. Short life cycle is an important characteristic of VE, especially the VE in fashion industry, which is a field of growing importance in economy and e-commerce [5-7]. In spite of substantial advantages of $\mathrm{VE}$, there are a number of problems associated with them that may threaten the success of VE. Das and Teng [8] have pointed out that the main two kinds of risk in alliances are performance risk and relational risk. Performance risk is the probability that a VE may fail even when partners commit themselves fully to the VE. Relational risk is concerned with probability that member enterprises lack commitment to the VE and that their possible opportunistic behavior could undermine the prospects of a VE. Enterprises form VE to reduce performance risk but induce relationship risk. Generally, partners tend to be more interested in pursuing their self-interest than the common interest of the alliance. Partners are primarily motivated in enhancing their selfinterest at the cost of other partners and even the owner, which is in fact the moral hazard that threatens the success of VE, and such opportunistic behaviors include shirking, appropriating the member enterprise's resources, distorting information, harboring hidden agendas, and delivering 
unsatisfactory products and services. As these activities seriously jeopardize the viability of a VE, relational risk is an important component of the overall risk in VEs. Moral hazard is a kind of serious relationship risk [9].

As the partners are prone to shirk production tasks because efforts are unobservable. We consider the owner endowed with personally costly monitoring technology providing contractible noisy signals about providing information about the partners' effort undertaken to produce output. Our modeling choices are guided by principal agent and monitoring theory [10]. Monitoring and associated incentive contracts are another way to combat shirking [10]. In our paper, monitoring strategy is represented as an activity that is personally costly to individual partners and which produces informative signals of partners' efforts. The benefits of monitoring to the owner are twofold; it can prevent the partners from shirking but it is costly, which is a trade-off. Traditional contract models are based on risk neutrality, where decision makers make decisions to maximize their expected profits. In the last decade or so researchers have called for riskaverse models for supply chain management to reflect the risk preferences in decision making in order to represent more realistic settings [11]; that is, in the field of economics, players often have risk preference rather than risk neutral. Based on the related literatures of profit and risk sharing in supply chain [12-15], fashion supply chain [5-7], partnerships $[10,16]$, and joint ventures $[17,18]$, the linear compensation contract with downside risk constraints in a VE composed of a risk-neutral owner and $n$ risk-averse partners is proposed in this paper. Partners choose the effort level simultaneously to maximize their expected net profits, but with a stipulation that their downside risk is limited while the owner exerts the monitoring efforts with corresponding monitoring cost. We then solve the model and characterize optimal productive efforts, incentive intensity, and monitoring efforts with risk attitude in the compensation contract and then compare them to the no monitoring scenario and show that selecting the partners of lower risk-averse and implementing certain level of monitoring is necessary.

The remainder of this paper is organized as follows. In Section 2, a brief review of related literature is provided. In Section 3, the basic revenue sharing problem with downside risk constraints of fashion VE is proposed, which is analyzed in Section 4. In Section 5, the contract analysis to make further investigations of the revenue sharing contract and the result for no monitoring contract is briefly presented for comparison purposes. Due to the complexity of the closedform solutions, we present numerical examples and provide managerial observations in Section 6. Finally the conclusions and some areas of future research are given in Section 7.

\section{Related Literature}

This paper mainly studies revenue sharing contract of VE for fashion industry with risk preference. In the following, we provide a brief review of papers that relate to mechanism design and risk management.
At present, risk management of VE has received considerable research attentions. Various contractive decisions are developed to provide a more scientific and effective way for managing the risk of VE [19-21]. Unfortunately, there are few researchers going deep into these problems of contract design, especially the profit sharing contract considering risk preference in VE, though VE arrests a lot of attention. We could get some useful suggestion from the fields of supply chains [12-15], fashion supply chain [5-7], partnerships [10, $16]$, and joint ventures $[17,18,22]$, as they have many common characteristics with VE. Gan et al. [13] take up the issue of coordination in supply chains involving risk-averse agents and develop coordinating contracts in three specific cases according to the supplier and retailer's risk attitude. Then they design a contract to achieve the set of Pareto-optimal solutions. They further investigate a supply contract involving a risk-neutral supplier and a downside risk-averse retailer and design a risk-sharing contract that offers the desired downside protection to the retailer, provides respective reservation profits to the agents, and accomplishes channel coordination [23]. Huddart and Liang [10] have studied the profit sharing and monitoring in partnerships, they considered partnerships among risk-averse professionals endowed with a risky and personally costly production technology and a personally costly monitoring technology providing contractible noisy signals about partners' productive efforts. Every partner performs the same tasks and has the same characteristics. The authors illustrated partners' productive and monitoring efforts under different monitoring mechanisms. Bai et al. [22] present a model of team production which incorporates the revenue-sharing contract in joint ventures with 2 enterprises into the property-rights and the transaction-cost theories of the firm and emphasizes the impact of expropriation. It shows that joint control can be optimal as well as unilateral control.

From the related literature review, we found that researchers had carried out some valuable investigations on the profit and risk sharing in supply chain, joint ventures, and partnerships, even VE. Most of the literature focuses on the criteria of minimizing expected cost or maximizing expected profit. In fact, what a manager concerns mostly is not only profit but also the risk or loss of their alliance. Thus, designing supply contracts is devoted to improve the expected value of a given performance measure. In the field of economics, agents are often assumed to be risk averse. In addition to fuzzy evaluation [20, 21, 24, 25], case study approach [26], almost all of the papers described risk-aversion by a concave utility function or a mean-variance tradeoff which is widely used in theoretical studies. This paper uses downside risk measure to describe the risk. The mean-variance approach works best when the random component is normally distributed. But this is not the case in some problems such as the newsvendor problem or others. Mean-variance analysis is an important operational approach to deal with tradeoff between reward and risk $[7,13,15]$. The mean-variance measure satisfies a class of decision makers with concave quadratic utility function, but it is inadequate. As the variance is the expectation of the square of the deviations of a random variable from its mean value, it is also a mean value. The mean value is an average based on the probability; it mainly reflects the event 
with relatively high probability while ignoring small sample problem. In fact often the neglected rare events lead to high risk. The variance is only an average, a reference value; we cannot obtain the probability value to realize the value while the downside risk has the corresponding confidence level. The idea about downside risk is that the left-hand side of a return distribution involves risk while the right-hand side contains the better investment opportunities. The variance equally penalizes desirable upside influence and undesirable downside outcomes $[27,28]$. Therefore, decision maker may consider his downside risk criterion to be more important than simply the variance of his profit. This paper aims to do it by a simple downside risk measure to consider the risk taking and preferences.

\section{Problem Formulation}

In this section, the downside risk is adopted as the risk decision criterion. Then the optimal decision making problem of a VE in fashion industry involving constraints limiting the partners' downside risk is described.

3.1. Downside Risk. Now the downside risk is described formally. A general definition of downside risk for a choice of the decision pair $(T, p)$ is $[23,27,28]$

$$
\gamma=P\{\pi \leq T\} \leq p,
$$

where $T$ denotes the target profit; then the downside risk of the partner is defined to be the probability that his net profit is no greater than $T$ and $\gamma$ is the downside risk measure. The pair $(T, p)$ reflects the degree of risk aversion for the partner.

This problem is a chance constraint problem [29]; the target level $T$ could be associated with bankruptcy or something less drastic. Furthermore, if the decision maker is loss averse, then $p$ can be set to 0 . For risk-aversion pairs $\left(\alpha^{1}, \beta^{1}\right)$ and $\left(\alpha^{2}, \beta^{2}\right)$, if $\alpha^{1} \leq \alpha^{2}$ and $\beta^{1} \geq \beta^{2}$, then pair $\left(\alpha^{2}, \beta^{2}\right)$ means a higher aversion to risk than $\left(\alpha^{1}, \beta^{1}\right)$; otherwise we cannot compare the extent of risk aversion implied by these pairs. The downside risk constraint is known as a chance constraint in the operations research literature [29]. As the downside risk measure is a special case of LPM; it is equivalent to a $\mathrm{VaR}$ constraint, which requires that the worst loss given a confidence level be less than a given bound and is often used in the finance [23].

3.2. Problem Description. In this paper, a fashion VE involving a risk-neutral owner and a set $N=\{1,2, \ldots, n\}$ of $n$ downside risk-averse partners is considered. The owner relies on the partners to produce the products and designs compensation contracts for the partners after the output is realized. The sequence of events is as follows. (1) At the beginning, the owner offers a take-it-or-leave-it revenue sharing contract in accordance with the partners' characteristic including risk preference and decides the corresponding monitoring effort level. $M=\left(m_{1}, m_{2}, \ldots, m_{n}\right)\left(m_{i} \geq 0, i \in N\right)$ to the partners simultaneously. (2) The partner decides whether or not to accept the contract. (3) If the partner accepts, it then exerts a level of unobservable productive effort, $a_{i} \geq 0$ privately and noncooperatively. (4) The output is realized and the owner compensates each partner according to the chosen contract. Both productive and monitoring efforts are personally costly to the partners and owner. Denote the convex cost function of partner $i$ as $C_{i}\left(a_{i}\right), i \in N$, and $C_{i}^{\prime}\left(a_{i}\right)>0, C_{i}^{\prime \prime}\left(a_{i}\right)>$ 0 , that is, continuously differentiable and strictly convex. To simplify the analysis, we restrict that the convex cost function takes the form as $C_{i}\left(a_{i}\right)=b_{i} a_{i}^{2} / 2, i \in N$. The owner's total monitoring cost functions to all partners as $C\left(m_{1}, m_{2}, \ldots, m_{n}\right)=\sum_{i \in N} l_{i} m_{i}(C(M))$, where $b_{i}$ and $l_{i}$ are the margin coefficient of cost. For convenience, we will refer to the owner as "she" and the agent as "he" hereafter.

The output of the alliance $\pi=\sum_{i \in N} \pi_{i}$ is realized and the effort supervised by the owner, who receives her payoff from the output and pays the partners based on her observations $\bar{a}_{i}$, a public signal about the effort of partner $i$, is given by $\bar{a}_{i}=$ $a_{i}+\eta_{i}, i \in N$, where $\eta_{i} \sim N\left(0, g\left(m_{i}\right)\right)$, the nosily of the owner's observables arising from the actual effort level of partner $i$, $g\left(m_{i}\right)$, the variance of $\eta_{i}$; it reflects the accuracy of the owner's observables [10] and is decreasing in $m_{i}$, that is, $g^{\prime}\left(m_{i}\right)<0$, $\left|g\left(m_{i}\right)\right| \leq g(0)=L$. As the owner's observables will be more stable if he pays more effort, so $g\left(m_{i}\right)$ is decreased in his monitoring effort $m_{i}$. So to simplify the analysis, we assume that $g\left(m_{i}\right)$ is differentiable and convex and takes the following form:

$$
g\left(m_{i}\right)=\frac{L}{1+m_{i}} .
$$

As the actual productive effort level $a_{i}$ is unobservable, and the incentive intensity depends on the owner's observations $a_{i}$, so moral hazard cannot be eliminated if the owner and partners lack information about the actions of the other partners, and the partners are subject to moral hazard, and this behavior is unavoidable if the VE output is the only contractible variable.

Now, the basic particular revenue sharing model will be present. To simplify the analysis, the output function is restricted to simple forms since this is adequate to provide a number of valuable insights into the revenue sharing contract. The contribution to the VE output is random with a mean that increases in the partner's effort and does not depend on the effort choices of other partners, which considerably simplifies the analysis; that is, the output function of the VE is assumed to be a linear function of the partners' productive efforts and is assumed to be $\pi_{i}=k_{i} a_{i}+\varepsilon, i \in N$, the owner's incentive intensity depends on $\bar{\pi}_{i}=k_{i} \bar{a}_{i}+\varepsilon, i \in N$, and $k_{i}$ is the margin coefficient. The linear sharing rules and normally distributed random variables are employed in this paper, that is, adopt agency model developed by literature [9]. which has been proved to be much more tractable in addressing multiaction and multiperiod models. The revenue sharing function is assumed to be linear in the output, such as the linear sharing rules $s_{i}\left(\bar{a}_{i}, \pi_{i}\right)=\alpha_{i}+\beta_{i} \bar{\pi}_{i}$, the base salary $\alpha_{i}$, and the commission rate $\beta_{i}, i \in N$. The exogenous risk variables of the alliance are assumed to be independently and normally distributed, that is, $\varepsilon \sim N\left(0, \sigma^{2}\right)$. Such models have been used in accounting and economics. 
Under this linear contract, the net profit of partner $i$ is given by

$$
\begin{array}{r}
w_{i}=s_{i}\left(\bar{a}_{i}, \pi_{i}\right)-C_{i}\left(a_{i}\right)=\alpha_{i}+\beta_{i}\left[k_{i}\left(a_{i}+\eta_{i}\right)+\varepsilon\right]-\frac{b_{i} a_{i}^{2}}{2}, \\
i \in N .
\end{array}
$$

Due to his risk preference $\left(U_{i}, p_{i}\right), i \in N$, where $U_{i}$ denotes his target profit level, $p_{i}$ is the probability that his actual profit should not fall below his target profit, from the definition of downside risk in Section 3.1, the downside risk constraint of partner $i$ is

$$
P\left\{w_{i}=s_{i}\left(\bar{a}_{i}, \pi_{i}\right)-C_{i}\left(a_{i}\right) \leq U_{i}\right\} \leq p_{i} .
$$

Then his objective is to maximize his own expected profit under its downside risk constraint by choosing the optimal $a_{i}$, and this is concave in $a_{i}$, that is,

$$
\max _{a_{i} \geq 0} E\left(w_{i}\right)
$$

subject to

$$
P\left\{w_{i} \leq U_{i}\right\} \leq p_{i} .
$$

As the owner's observables are costly to the monitoring efforts $m_{i}$ and take the total cost as $C(M)$, the budget balancing requires that the total output of $\mathrm{VE}$ should be divided among all the members including the owner. Therefore, the owner's net profit function can be written as

$$
\begin{aligned}
U & =\pi-\sum_{i \in N} s_{i}\left(\bar{a}_{i}, \pi_{i}\right)-C(M) \\
& =\sum_{i \in N}\left(1-\beta_{i}\right)\left[k_{i}\left(a_{i}+\eta_{i}\right)+\varepsilon\right]-\sum_{i \in N} \alpha_{i}-\sum_{i \in N} l_{i} m_{i} .
\end{aligned}
$$

Similar to principal-agent framework [30,31], the partner acts as the follower, and the owner as a leader designs the revenue sharing contracts $S=\left\{s_{1}\left(\bar{a}_{1}, \pi_{1}\right), s_{2}\left(\bar{a}_{2}, \pi_{2}\right)\right.$, $\left.\ldots, s_{n}\left(\bar{a}_{n}, \pi_{n}\right)\right\}$ to maximize her expected profit while satisfying the partner's individual downside risk constraints (DC) and incentive compatibility constraints (IC). The owner's optimal incentive strategy satisfies the solution to the following problem:

$$
\max _{\alpha_{i}, \beta_{i}, m_{i}} E U=\sum_{i \in N}\left(1-\beta_{i}\right) k_{i} a_{i}-\sum_{i \in N} \alpha_{i}-\sum_{i \in N} l_{i} m_{i}
$$

subject to

$$
\text { (DC) } P\left\{w_{i}=\alpha_{i}+\beta_{i}\left[k_{i}\left(a_{i}+\eta_{i}\right)+\varepsilon\right]-\frac{b_{i} a_{i}^{2}}{2} \leq U_{i}\right\} \leq p_{i}
$$

(IC) $a_{i}$

$$
=\arg \max \left\{E w_{i}=E\left(\alpha_{i}+\beta_{i}\left[k_{i}\left(a_{i}+\eta_{i}\right)+\varepsilon\right]-\frac{b_{i} a_{i}^{2}}{2}\right)\right\},
$$

Equation (9) is the DC constraint of partner $i$, and (10) is his IC constraint.

\section{The Optimal Strategy}

To solve the model in Section 3.2, the backward inductive method is adopted; at first, the partners' optimal choices of optimal productive effort are chosen simultaneously, and then the owner's optimal contract parameters such as incentive intensity and monitoring effort level are worked out. The partners' optimal choices and then the optimal contract parameters under the revenue sharing contract were characterized in this section. A discussion of the results is also provided.

The risk-averse preference parameter $p_{i}$ is set as $0<p_{i} \leq$ 0.5 , and this is equivalent to $\Phi^{-1}\left(p_{i}\right) \leq 0$, where $\Phi(\cdot)$ is the cumulative probability function for the standard normal distribution $N(0,1)$, and $\Phi^{-1}(\cdot)$ is its inverse function. Then, the usual transformation of the downside risk constraints (9) to traditional determined constraints is

$$
U_{i}+\frac{b_{i} a_{i}^{2}}{2}-\alpha_{i} \leq \beta_{i}\left(k_{i} a_{i}+\Phi^{-1}\left(p_{i}\right) \sqrt{\sigma^{2}+k_{i}^{2} g\left(m_{i}\right)}\right) .
$$

Firstly, the partners' optimal choices of productive effort level will be investigated. From the first-order derivatives on the productive effort we can get (12); that is, the partner's incentive compatibility constraints can be replaced by firstbest effort levels as

$$
a_{i}=\frac{k_{i} \beta_{i}}{b_{i}}
$$

Note that the second-order derivatives on $a_{i}$ are satisfied; then the model can be simplified as

$$
\max _{\alpha_{i}, \beta_{i}, m_{i}} E U=\sum_{i \in N}\left(1-\beta_{i}\right) k_{i} a_{i}-\sum_{i \in N} \alpha_{i}-\sum_{i \in N} l_{i} m_{i}
$$

Subject to (11) and (12).

The following result provides a necessary approach for the contract to be implementable, namely, to make each partner select the optimal effort for him.

Proposition 1. The optimal monitoring effort level $m_{i}^{*}$ is determined by (14)

$$
\frac{1}{\sqrt{\sigma^{2}+x}}=\frac{A}{x^{2}}+B
$$

where $A=-2 l_{i} L k_{i}^{2} / \Phi^{-1}\left(p_{i}\right) ; B=-b_{i} \Phi^{-1}\left(p_{i}\right) / k_{i}^{2} ; m_{i}=$ $L k_{i}^{2} / x-1$.

Proof. At optimality, the IC and DC conditions are binding; after substituting (12) and base salary in the original problem we have the objective function reduced to

$$
\begin{aligned}
f=\sum_{i \in N} \frac{k_{i}^{2} \beta_{i}}{b_{i}} & +\sum_{i \in N} \beta_{i} \Phi^{-1}\left(p_{i}\right) \sqrt{\sigma^{2}+k_{i}^{2} g\left(m_{i}\right)} \\
& -\sum_{i \in N} \frac{k_{i}^{2} \beta_{i}^{2}}{2 b_{i}}-\sum_{i \in N} l_{i} m_{i}-\sum_{i \in N} U_{i},
\end{aligned}
$$


where $f$ can be proofed to be jointly concave in $\beta_{i}$ and $m_{i}$, so the first-order derivatives are therefore necessary and sufficient, which yields the first-best $\beta_{i}$ and $m_{i}$ :

$$
\begin{gathered}
\frac{\partial f}{\partial \beta_{i}}=\frac{k_{i}^{2}}{b_{i}}+\Phi^{-1}\left(p_{i}\right) \sqrt{\sigma^{2}+k_{i}^{2} g\left(m_{i}\right)}-\frac{k_{i}^{2} \beta_{i}}{b_{i}}=0 \\
\frac{\partial f}{\partial m_{i}}=\frac{\beta_{i} \Phi^{-1}\left(p_{i}\right) k_{i}^{2} g^{\prime}\left(m_{i}\right)}{2 \sqrt{\sigma^{2}+k_{i}^{2} g\left(m_{i}\right)}}-l_{i}=0 .
\end{gathered}
$$

The second-order derivatives are

$$
\begin{gathered}
\frac{\partial^{2} f}{\partial \beta_{i}^{2}}=-\frac{k_{i}^{2}}{b_{i}}<0, \quad i \in N \\
\frac{\partial^{2} f}{\partial m_{i}^{2}}=\frac{\beta_{i} \Phi^{-1}\left(p_{i}\right) k_{i}^{2}}{2\left(\sigma^{2}+k_{i}^{2} g\left(m_{i}\right)\right)^{3 / 2}} \\
*\left[g^{\prime}\left(m_{i}\right)\left(\sigma^{2}+k_{i}^{2} g\left(m_{i}\right)\right)-\frac{k_{i}^{2} g^{\prime 2}\left(m_{i}\right)}{2}\right]<0 \\
\frac{\partial^{2} f}{\partial \beta_{i} \partial m_{i}}=\frac{\Phi^{-1}\left(p_{i}\right) k_{i}^{2} g^{\prime}\left(m_{i}\right)}{2 \sqrt{\sigma^{2}+k_{i}^{2} g\left(m_{i}\right)}}>0 .
\end{gathered}
$$

We obtain the Hessian matrix by second-order derivatives from (17).

The first principal minor of the Hessian matrix is negative and the determinant is positive. That is negative definite concavity, which is the stagnation point, is maximum and guarantees the optimal solutions; that is, the first-order derivatives are therefore sufficient.

Substituting the specific form of $g\left(m_{i}\right)$ in the first-order derivatives and combining (16), the corresponding optimal monitoring effort level $m_{i}^{*}$ satisfies (14).

Due to the complex structure of quintic equation (14), the closed-form solutions for the optimal contract parameters $m_{i}^{*}$ cannot be derived, but the analytical results on how the optimal contract parameters change with $m_{i}^{*}$ can be derived in Section 5. From the second-order derivatives and negative Hessian matrix, the optimal decisions are unique and be derived from (16).

\section{Analysis and Discussion}

In this section, to illustrate the performance of the optimal strategies in Section 4, we will first study the optimal strategy in case no monitoring is used, which will be taken as a benchmark case. Then, the monitoring optimal contract is analyzed and the corresponding analytical results will be studied and compared in more detail below, where subscript $\left({ }^{* *}\right)$ denotes no monitoring scenario and $\left({ }^{*}\right)$ denotes monitoring case, respectively.

5.1. No Monitoring Contract. In this subsection, in order to have a better understanding of our model, the special case with no monitoring strategy as the benchmark case, that is, $m_{i}=0$, is used to make further investigation and compare the results with monitoring scenario. The comparison is illustrated as follows. When the owner pays no monitoring effort, the error of the signal to the partners' effort reaches its maximum as

$$
m_{i}=0, \quad g(0)=L, \quad \eta_{i} \sim N(0, L) .
$$

From the model in Section 3, the corresponding optimal choice can be derived as

$$
\begin{gathered}
\beta_{i}^{* *}=1+\frac{b_{i} \Phi^{-1}\left(p_{i}\right) \sqrt{\sigma^{2}+k_{i}^{2} L}}{k_{i}^{2}}, \\
a_{i}^{* *}=\frac{k_{i} \beta_{i}^{* *}}{b_{i}} .
\end{gathered}
$$

The optimal expected net profit of partner $i$ is

$$
\begin{aligned}
E w_{i}^{* *}= & U_{i}-\Phi^{-1}\left(p_{i}\right) \sqrt{\sigma^{2}+k_{i}^{2} L} \\
& *\left(1+\frac{b_{i} \Phi^{-1}\left(p_{i}\right) \sqrt{\sigma^{2}+k_{i}^{2} L}}{k_{i}^{2}}\right) .
\end{aligned}
$$

The optimal risk attitude $p_{i}^{* *}$ satisfies

$$
\Phi^{-1}\left(p_{i}^{* *}\right)=-\frac{k_{i}^{2}}{2 b_{i} \sqrt{\sigma^{2}+k_{i}^{2} L}} .
$$

The corresponding maximum expected profit is

$$
E w_{i}^{* *}=U_{i}+\frac{k_{i}^{2}}{4 b_{i}} .
$$

5.2. Monitoring Contract. After the optimal productive effort and monitoring effort level for each partner is determined, the optimal contract parameters $\beta_{i}^{*}, m_{i}^{*}$, and $a_{i}^{*}$ could be solved from the optimization problem (13).

From (15), the first-best commission rate is

$$
\beta_{i}^{*}=1+\frac{b_{i} \Phi^{-1}\left(p_{i}\right) \sqrt{\sigma^{2}+k_{i}^{2} g\left(m_{i}^{*}\right)}}{k_{i}^{2}} .
$$

The first-order derivatives are

$$
\frac{\partial \beta_{i}^{*}}{\partial m_{i}^{*}}=\frac{b \Phi^{-1}\left(p_{i}\right) g^{\prime}\left(m_{i}^{*}\right)}{2 k_{i}^{2} \sqrt{\sigma^{2}+k_{i}^{2} g\left(m_{i}^{*}\right)}}>0 .
$$

Equation (24) shows that the optimal incentive intensity $\beta_{i}^{*}$ is monotonic (increasing) in the owner's optimal monitoring effort level $m_{i}^{*}\left(m_{i}^{*} \uparrow\right)$.

From (12), we can get the optimal effort $a_{i}^{*}=k_{i} \beta_{i}^{*} / b_{i}$.

Further we get that

$$
\frac{\partial a_{i}^{*}}{\partial m_{i}^{*}}=\frac{\Phi^{-1}\left(p_{i}\right) g^{\prime}\left(m_{i}^{*}\right)}{2 k_{i} \sqrt{\sigma^{2}+k_{i}^{2} g\left(m_{i}^{*}\right)}}>0 .
$$


Equation (25) means that the higher the level of the owner's monitoring effort is, the more productive effort the partner will choose $\left(m_{i}^{*} \uparrow\right)$; otherwise, he prefers to choose low productive effort.

We find an obvious result that the partners prefer to choose high productive effort when they are strongly monitoring $\left(m_{i}^{*} \uparrow\right)$; that is to say, monitoring strategy can prevent shirking problem effectively.

Obviously, the partner who shares more from the VE's output should bear more risk $\left(p_{i} \uparrow\right)$, as $\beta_{i}^{*}$ has to be increasing in $p_{i}$. From the mean-variance risk measure, high $\beta_{i}^{*}$ means high risk, which is in accordance with the downside risk measure $[9,32]$. Considering combinations with $(12), a_{i}^{*}$ is also increasing in $p_{i}$ which means that the less risk averse the partner is, the more productive effort he will choose $\left(p_{i} \uparrow\right)$.

The optimal expected net profit of partner $i$ is

$$
\begin{aligned}
E w_{i}^{*}= & U_{i}-\Phi^{-1}\left(p_{i}\right) \sqrt{\sigma^{2}+k_{i}^{2} g\left(m_{i}^{*}\right)} \\
& *\left(1+\frac{b_{i} \Phi^{-1}\left(p_{i}\right) \sqrt{\sigma^{2}+k_{i}^{2} g\left(m_{i}^{*}\right)}}{k_{i}^{2}}\right) .
\end{aligned}
$$

When the degree of risk aversion level $p_{i}^{*}$ satisfies

$$
\Phi^{-1}\left(p_{i}^{*}\right)=-\frac{k_{i}^{2}}{2 b_{i} \sqrt{\sigma^{2}+k_{i}^{2} g\left(m_{i}^{*}\right)}} .
$$

$E w_{i}^{*}$ reaches the maximum as $E w_{i}^{*}=U_{i}+k_{i}^{2} / 4 b_{i}$.

If $\Phi^{-1}\left(p_{i}\right) \leq-k_{i}^{2} /\left(2 b_{i} \sqrt{\left.\sigma^{2}+k_{i}^{2} g\left(m_{i}^{*}\right)\right)}\right.$, the optimal expected net profit $E w_{i}^{*}$ of partner $i$ is increasing in $p_{i}$; if $\Phi^{-1}\left(p_{i}\right) \geq-k_{i}^{2} /\left(2 b_{i} \sqrt{\sigma^{2}+k_{i}^{2} g\left(m_{i}^{*}\right)}\right), E w_{i}^{*}$ is decreasing in $p_{i}$, which means that (27) is the optimal risk preference of partner $i$ under monitoring strategy.

Comparing $a_{i}^{*}$ with $a_{i}^{* *}$, we find that the partners prefer to choose higher productive effort when they are observed, which means that suitable monitoring strategy can reduce the moral hazard effectively.

Comparing $\Phi^{-1}\left(p_{i}^{* *}\right)$ with $\Phi^{-1}\left(p_{i}^{*}\right)$ (see (21) and (27)), we find that when the partners are monitored, the partners bare more risk even if the optimal expected is the same as $U_{i}+k_{i}^{2} / 4 b_{i}$.

\section{Numerical Examples}

In this section, we provide some numerical examples based on (24), (25), and (26). The purpose is twofold. First, the examples are used to illustrate the model developed in previous sections to make further investigation. Secondly, since the optimal $m_{i}^{*}$ and $\beta_{i}^{*}$ cannot be explicitly written as a function of related variables, it is difficult to obtain a closed-form expression for solving the optimal strategy. Thus we need to use the numerical examples in investigating the charismatic of the monitoring policy.

In the following numerical examples, we assign the related parameters as follows: $l_{i}=1, b_{i}=1, k_{i}=1, L=$

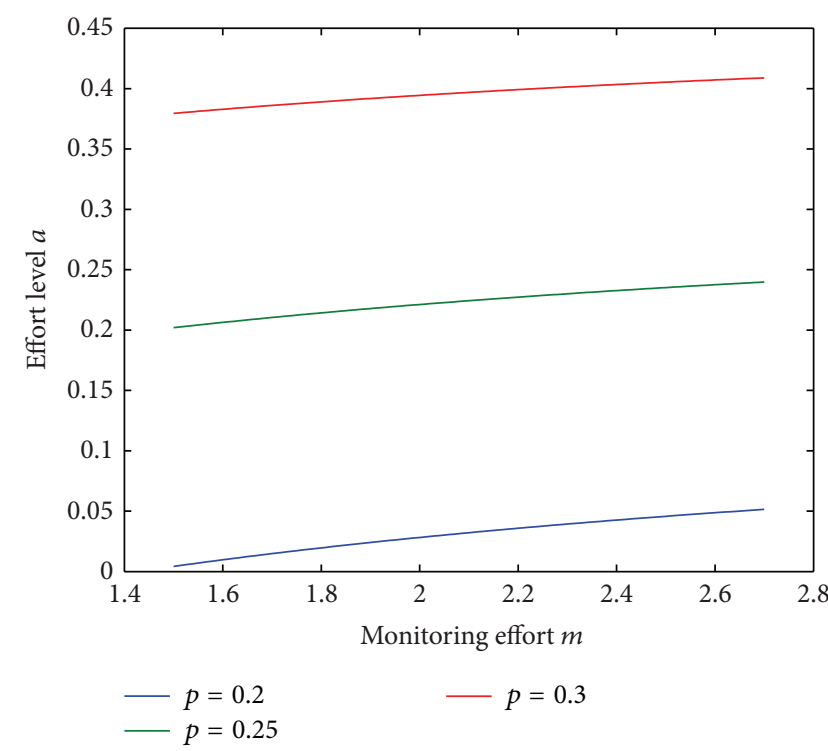

FIGURE 1: The optimal productive effort and the monitoring effort level.

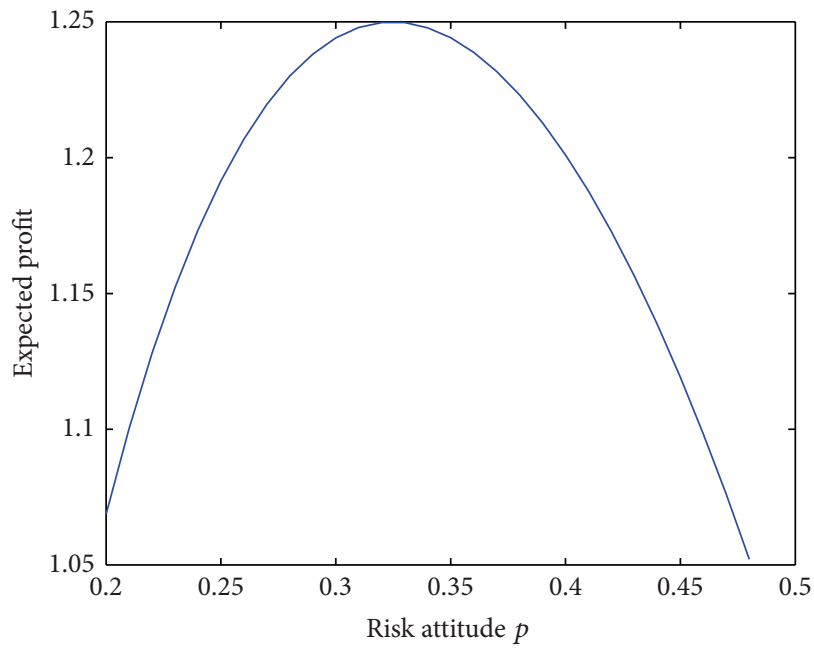

FIGURE 2: The partner's expected profit and risk preference $p_{i}$.

$0.5, U_{i}=1$, and $\sigma^{2}=1$. Figure 1 presents the partner's optimal effort level to three partners, $a_{i}^{*}$ (vertical axis), as a function of the owner's corresponding monitoring effort level $m_{i}^{*}$ (horizontal axis), under different risk aversion levels $\left(p_{i}=\right.$ $0.2,0.25$, and 0.3 ). From Figure 1, we could draw out that, as the risk aversion level $p_{i}$ or the monitoring effort increases, both the productive effort of every partner and the incentive intensity to them increase ((12) illustrates that the productive effort and the incentive intensity have the same trends, so we omit the figure of incentive intensity).

Next, we conduct computational study to investigate the impacts of partner's risk averse level on his expected profit. Figure 2 illustrates the results. The parameter settings are as follows: $m_{i}=1$ and other parameters are consistent with Figure 1. 
Figure 2 reveals that the partner's expected profit (vertical axis) is first increasing in his risk aversion level $p_{i}$ (horizontal axis) and then decreasing, which verifies (20) and (26).

\section{Conclusions and Future Research}

This paper investigates the revenue sharing contract in a fashion VE consisting of a risk-neutral owner and $n$ downside risk-averse partners contribute core efforts to the output of the alliance with the owner's costly monitoring strategy; the owner's monitoring strategy will be more stable with high level monitoring effort. We expect that the contract could maximize the expected net profit of every member in VE and reduce the moral hazard phenomena effectively by the incentive contract. From the analysis of the model, we can draw out some valuable conclusions as follows. The less risk averse the partner is, or the higher level of the owner's monitoring effort, the more productive the effort he will choose; otherwise, he prefers to choose low productive effort. This observation gives us the implication that implementing monitoring strategy can eliminate the moral hazard phenomena effectively.

The scope of this paper has necessarily been limited, and its coverage could be fruitfully extended in a number of interesting areas in future studies. For example, to simplify the analysis and explore the implications of the contract, the risk attitude is assumed to be known information; that is, the adverse selection problem in VE is omitted and some restrictions have een made in the analysis in Section 4, such as linear/quadratic forms, independence, and normal distribution. In the future research, we will relax these restrictions to investigate the risk and revenue sharing contract under much more general environment and consider the incentive contract when the relationship between the partners is cooperative; additional research needs to cite the conditional value-at-eisk $(\mathrm{CVaR})$ crition as risk measure [33].

Future work also includes extending the primal model to behavioral economics context, behavioral operation research especially the fairness/equity supported strongly by experiments. As fairness/equity is important for members' relationship in VE, people and firms are intrinsically fair-minded; to qualify partners' concerns of fairness, we will model the interaction between a risk neutral, net profit maximizing owner, and risk averse utility maximizing partners who are inequity averse towards the others with fairness preferences psychology.

\section{Conflict of Interests}

The authors declare that there is no conflict of interests regarding the publication of this paper. The authors declare that they have no financial and personal relationships with other people or organizations that can inappropriately influence their work; there is no professional or other personal interest of any nature or kind in any product, service, and/or company that could be construed as influencing the position presented in, or the review of, the paper.

\section{Acknowledgments}

The authors sincerely thank the anonymous reviewers for their valuable comments and suggestions on the revision of the paper. This work is supported by the National Science Foundation for Distinguished Young Scholars of China under Grant nos. 71325002 and 61225012; the National Natural Science Foundation of China under Grant no. 71071028; the Specialized Research Fund of the Doctoral Program of Higher Education for the Priority Development Areas under Grant no. 20120042130003; the Specialized Research Fund for the Doctoral Program of Higher Education under Grant no. 20110042110024; the Fundamental Research Funds for the Central Universities under Grant nos. N110204003 and N120104001; the Fundamental Research Funds for State Key Laboratory of Synthetical Automation for Process Industries under Grant no. 2013ZCX11; the Jiangsu Postdoctoral Science Research Foundation under Grant no. 1401130C; the Foundation for Key Research Base of Philosophy and Social Science in Colleges and Universities of Jiangsu Province under Grant no. 2014SJD411.

\section{References}

[1] X. Wang, T. N. Wong, and G. Wang, "An ontological intelligent agent platform to establish an ecological virtual enterprise," Expert Systems with Applications, vol. 39, no. 8, pp. 7050-7061, 2012.

[2] L. M. Camarinha-Matos, "Execution system for distributed business processes in a virtual enterprise," Future Generation Computer Systems, vol. 17, no. 8, pp. 1009-1021, 2001.

[3] M. T. Martinez, P. Fouletier, K. H. Park, and J. Favrel, "Virtual enterprise-organisation, evolution and control," International Journal of Production Economics, vol. 74, no. 1-3, pp. 225-238, 2001.

[4] T. Kim, S. Lee, K. Kim, and C. Kim, "A modeling framework for agile and interoperable virtual enterprises," Computers in Industry, vol. 57, no. 3, pp. 204-217, 2006.

[5] A. Pan and T. M. Choi, "An agent-based negotiation model on price and delivery date in a fashion supply chain," Annals of Operations Research, 2013.

[6] S. Costantini, G. de Gasperis, A. Provetti, and P. Tsintza, "A heuristic approach to proposal-based negotiation: with applications in fashion supply chain management," Mathematical Problems in Engineering, vol. 2013, Article ID 896312, 15 pages, 2013.

[7] M. Xu, Q. Wang, and L. Ouyang, "Coordinating contracts for two-stage fashion supply chain with risk-averse retailer and price-dependent demand," Mathematical Problems in Engineering, vol. 2013, Article ID 259164, 12 pages, 2013.

[8] T. K. Das and B. S. Teng, "Managing risks in strategic alliances," Academy of Management Executive, vol. 13, no. 4, pp. 50-62, 1999.

[9] B. Holmström and P. Milgrom, "Aggregation and linearity in the provision of intertemporal incentives," Econometrica, vol. 55, no. 2, pp. 303-328, 1987.

[10] S. Huddart and P. J. Liang, "Profit sharing and monitoring in partnerships," Journal of Accounting and Economics, vol. 40, no. 1-3, pp. 153-187, 2005. 
[11] Y. Dai and X. Chao, "Salesforce contrast design and inventory planning with asymmetric risk-averse sales agents," Operations Research Letters, vol. 41, no. 1, pp. 86-91, 2013.

[12] G. P. Cachon and M. A. Lariviere, "Supply chain coordination with revenue-sharing contracts: strengths and limitations," Management Science, vol. 51, no. 1, pp. 30-44, 2005.

[13] X. Gan, S. P. Sethi, and H. Yan, "Coordination of supply chains with risk-averse agents," Production and Operations Management, vol. 13, no. 2, pp. 135-149, 2004.

[14] H. Krishnan and R. A. Winter, "On the role of revenue-sharing contracts in supply chains," Operations Research Letters, vol. 39, no. 1, pp. 28-31, 2011.

[15] T. Xiao and D. Yang, "Risk sharing and information revelation mechanism of a one-manufacturer and one-retailer supply chain facing an integrated competitor," European Journal of Operational Research, vol. 196, no. 3, pp. 1076-1085, 2009.

[16] M. Gaynor and P. Gertle, "Moral hazard and risk spreading in partnerships," "Journal of Economics, vol. 26, no. 4, pp. 591-613, 1995.

[17] N. D. Masako and N. M. Stoughton, "A bargaining approach to profit sharing in joint ventures," Journal of Business, vol. 62, no. 2, pp. 237-270, 1989.

[18] K. Waehrer, "Mechanisms for dividing labor and sharing revenue in joint ventures," Review of Economic Design, vol. 8, no. 4, pp. 465-477, 2004.

[19] J. Chen and J. F. Chen, "Study on revenue sharing contract in virtual enterprises," Journal of Systems Science and Systems Engineering, vol. 15, no. 1, pp. 95-113, 2006.

[20] M. Huang, F. Lu, W. Ching, and T. K. Siu, "A distributed decision making model for risk management of virtual enterprise," Expert Systems with Applications, vol. 38, no. 10, pp. 13208-13215, 2011.

[21] W. H. Ip, M. Huang, K. L. Yung, and D. Wang, "Genetic algorithm solution for a risk-based partner selection problem in a virtual enterprise," Computers and Operations Research, vol. 30, no. 2, pp. 213-231, 2003.

[22] C. Bai, Z. Tao, and C. Wu, "Revenue sharing and control rights in team production: Theories and evidence from joint ventures," RAND Journal of Economics, vol. 35, no. 2, pp. 277-305, 2004.

[23] X. Gan, S. P. Sethi, and H. Yan, "Channel coordination with a risk-neutral supplier and a downside-risk-averse retailer," Production and Operations Management, vol. 14, no. 1, pp. 80-89, 2005.

[24] M. Huang, X. W. Wang, F. Q. Lu, and H. L. Bi, "A coordination of risk management for supply chains organized as virtual enterprises," Mathematical Problems in Engineering, vol. 2013, Article ID 931690, 11 pages, 2013.

[25] M. Huang, W. H. Ip, H. Yang, X. Wang, and H. C. W. Lau, "A fuzzy synthetic evaluation embedded tabu search for risk programming of virtual enterprises," International Journal of Production Economics, vol. 116, no. 1, pp. 104-114, 2008.

[26] J. Karjalainen, T. Haahtela, K. Kim, and C. H. Kim, "Profit and risk sharing in a virtual enterprise," International Journal of Innovation and Technology Management, vol. 1, no. 1, pp. 75-92, 2004.

[27] D. Nawrocki, "A brief history of downside risk measures," Journal of Investing, vol. 8, no. 3, pp. 9-26, 1999.

[28] P. C. Fishburn, "Mean-risk analysis with risk associated with below-target returns," American Economic Review, vol. 67, no. 2, pp. 116-126, 1977.
[29] A. Charnes and W. W. Cooper, "Chance-constrained programming," Management Science, vol. 6, no. 1, pp. 73-79, 1959.

[30] A. Attar, E. Campioni, G. Piaser, and U. Rajan, "On multipleprincipal multiple-agent models of moral hazard," Games and Economic Behavior, vol. 68, no. 1, pp. 376-380, 2010.

[31] F. Ye and Y. N. Li, "Group multi-attribute decision model to partner selection in the formation of virtual enterprise under incomplete information," Expert Systems with Applications, vol. 36, no. 5, pp. 9350-9357, 2009.

[32] T. M. Choi and C. H. Chiu, "Mean-downside-risk and meanvariance newsvendor models: implications for sustainable fashion retailing," International Journal of Production Economics, vol. 135, no. 2, pp. 552-560, 2012.

[33] L. J. Zhu, K. S. Hong, and C. L. Lee, "Optimal ordering policy of a risk-averse retailer subject to inventory inaccuracy," Mathematical Problems in Engineering, vol. 2013, Article ID 951017, 8 pages, 2013. 


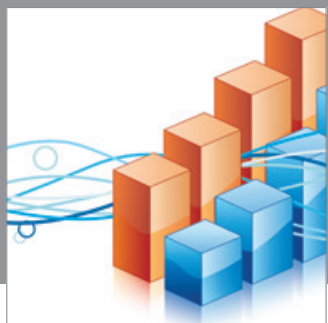

Advances in

Operations Research

mansans

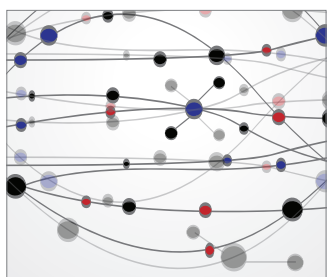

The Scientific World Journal
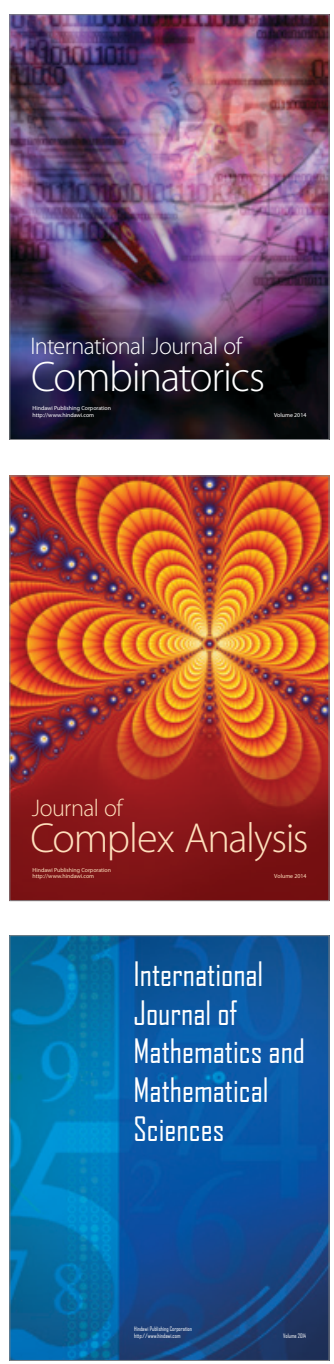
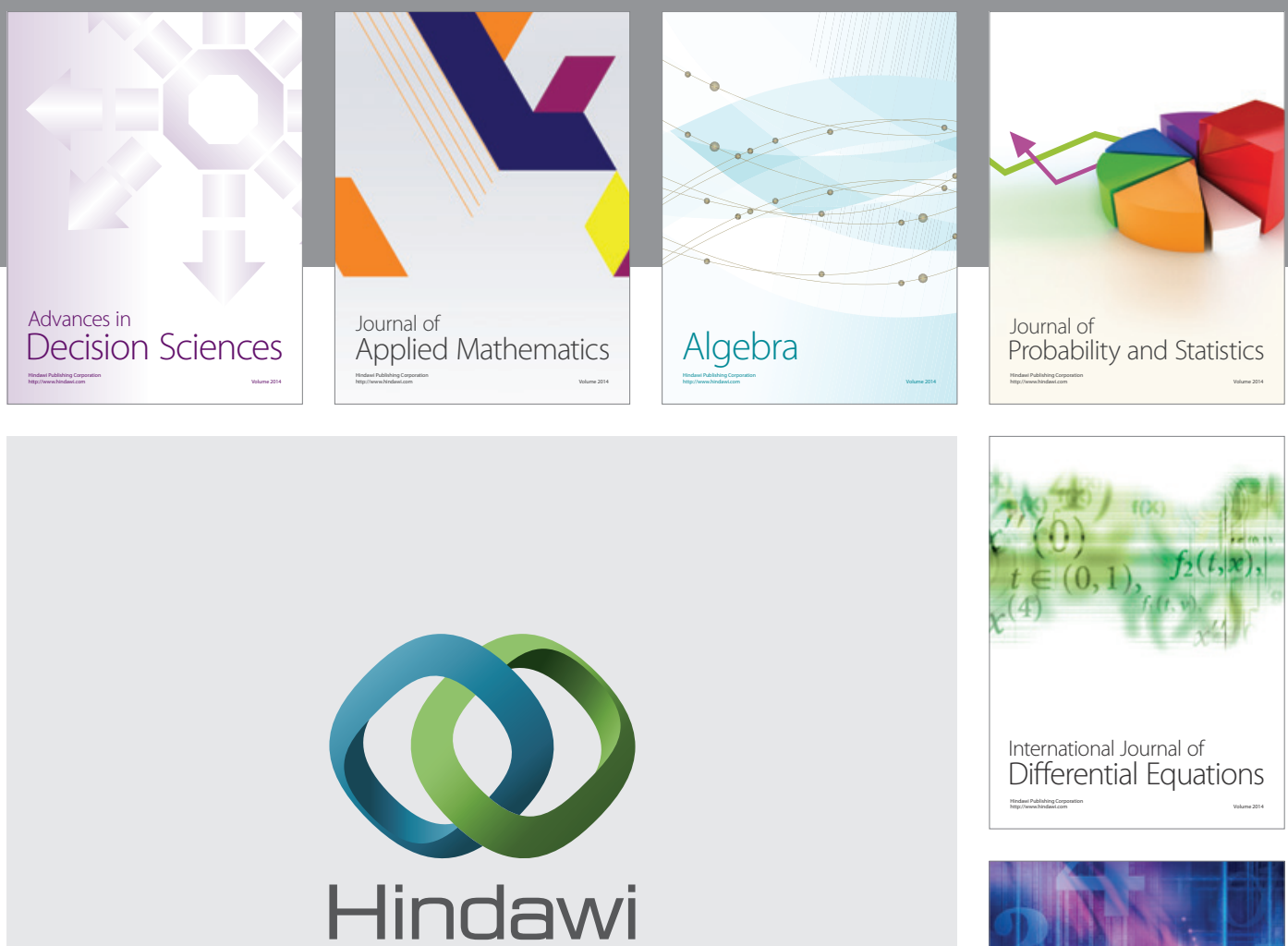

Submit your manuscripts at http://www.hindawi.com
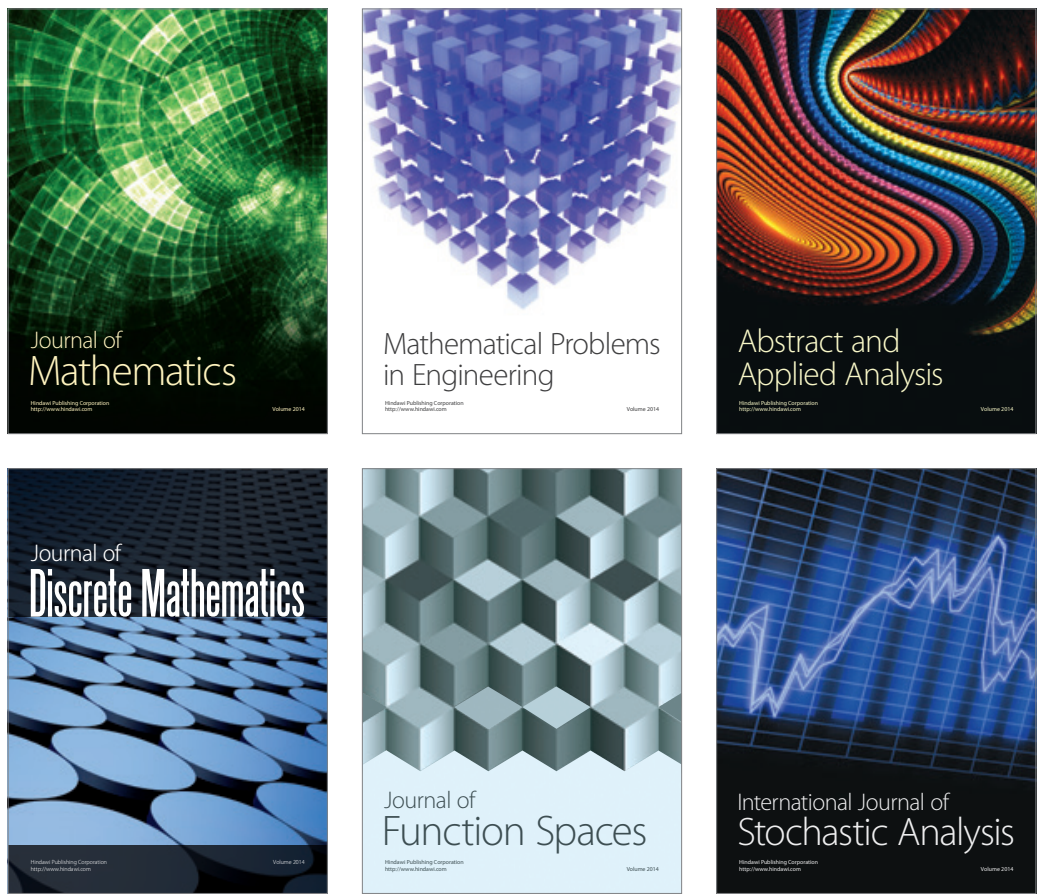

Journal of

Function Spaces

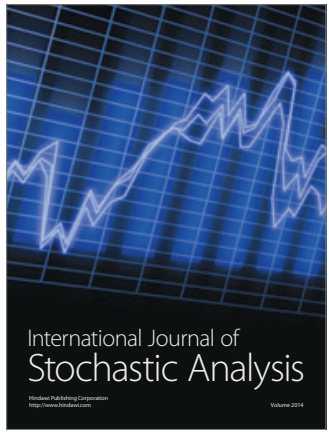

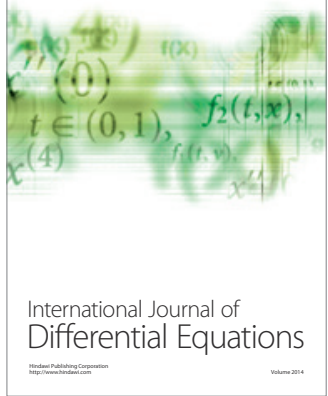
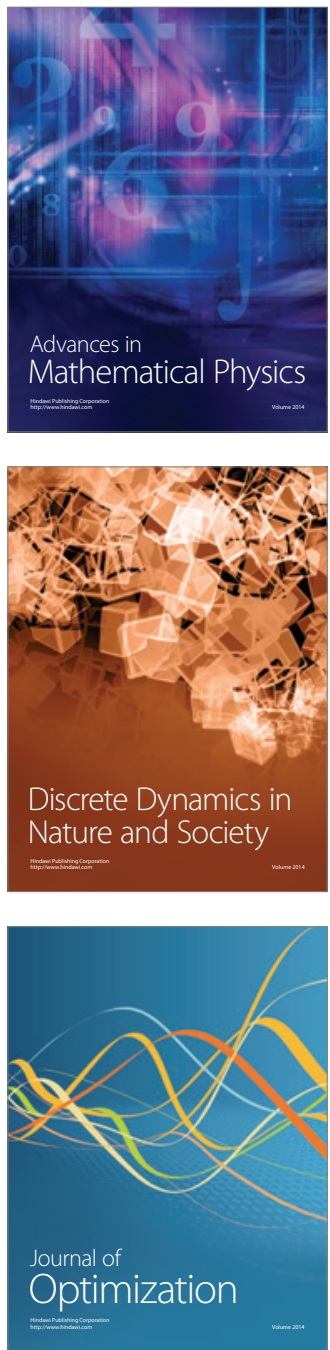